\title{
Central Nervous System Hemangioma
}

National Cancer Institute

\section{Source}

National Cancer Institute. Central Nervous System Hemangioma. NCI Thesaurus. Code C7004.

A hemangioma arising from the brain and spinal cord. 